Carla Aparecida Arena Ventura ${ }^{1}$ Anna Maria Meyer Maciel Rodríguez ${ }^{1}$ Elidia Aparecida Costa Bittencourt ${ }^{1}$ Emanuele Seicenti de Brito ${ }^{1}$

\title{
DIREITOS DAS PESSOAS COM TRANSTORNOS MENTAIS: A PERSPECTIVA DE QUEM CUIDA
}

Rights of people with mental disorders:

The perspective of caregivers

${ }^{1}$ Escola de Enfermagem de Ribeirão Preto. Universidade de São Paulo. Ribeirão Preto/SP, Brasil.

Correspondência: Carla Aparecida Arena Ventura. E-mail: caaventu@eerp.usp.br

Recebido: 13/02/2018. Revisão: 01/10/2019. Aprovado: 31/10/2019. 


\section{RESUMO}

Este é um estudo empírico de abordagem qualitativa com o objetivo de identificar a compreensão de profissionais de saúde sobre os direitos humanos fundamentais das pessoas com transtornos mentais. Os dados foram coletados por meio de entrevistas semiestruturadas com 26 profissionais de diversas categorias que participam do processo de internação dos usuários em um hospital especializado do interior paulista. As entrevistas foram gravadas, transcritas e interpretadas por meio de análise de conteúdo temática. Três unidades temáticas foram obtidas: profissionais de saúde mental e os direitos humanos das pessoas com transtornos mentais; conhecimento sobre os direitos humanos e o exercício da cidadania pelas pessoas com transtornos mentais; e atitudes profissionais com relação aos direitos humanos das pessoas com transtornos mentais. Concluiu-se que os profissionais reconheceram os direitos civis, políticos e sociais dos usuários, em especial o direito ao atendimento em saúde adequado e humanizado, à informação, à igualdade e à dignidade. Os profissionais afirmaram que a consciência sobre os direitos humanos permite cobrar e exigir sua garantia e respeito. Alguns trabalhadores admitiram seu papel de educadores quanto a esses direitos. Houve conexão entre conhecimento, conscientização e respeito aos direitos. Por outro lado, a falta de conhecimento e de compressão sobre os direitos e a falta de preparo dos trabalhadores pode interferir nas relações interpessoais no serviço, e a maioria deles presenciou situações de violações aos direitos humanos fundamentais.

\section{Palavras-Chave}

Transtornos Mentais; Direitos Humanos; Profissionais de Saúde.

\section{ABSTRACT}

An empirical study with a qualitative approach which has the objective of identifying the understanding of health professionals about the fundamental human rights of people with mental disorders. The data was collected through semi-structured interviews with 26 professionals from different categories who participate in the process of hospitalization of the patients in a specialized hospital in São Paulo countryside. The interviews were recorded, transcribed and interpreted through thematic content analysis. Three thematic units were obtained: mental health professionals and the human rights of people with mental disorders; knowledge about human rights and the exercise of citizenship by people with mental disorders; and professional attitudes towards the human rights of people with mental disorders. It was concluded that professionals recognized the civil, political and social rights of patients, especially the right to adequate and humane health care, information, equality and dignity. Professionals said that awareness of human rights allows them to collect and demand the assurance and respect of such rights. Some workers admitted their role as educators regarding these rights. There was a connection between knowledge, awareness and respect of rights. On the other hand, the lack of knowledge and understanding of rights and the lack of instruction of workers may interfere with interpersonal relations within the service, and most of the respondents witnessed situations of violations of fundamental human rights.

\section{Keywords}

Mental Disorder; Human Rights; Health Professionals. 


\section{Introdução}

A Declaração Universal dos Direitos Humanos, aprovada em 1948 pela Assembleia Geral da Organização das Nações Unidas (ONU), afirma em seu artigo $1^{\circ}$ que "todos os seres humanos nascem livres e iguais em dignidade e direitos". Portanto, os direitos são inerentes aos seres humanos sem distinção de qualquer espécie, como raça, cor, sexo, idioma, religião, opinião política, origem nacional ou social, riqueza, nascimento ou qualquer outra condição ${ }^{1}$. Apesar de todos terem direitos iguais inerentes à condição de ser humano, há disparidades no exercício de direitos por alguns grupos sociais, dentre elas as pessoas com transtornos mentais.

Definir transtorno mental é algo complexo, pois não se trata de uma condição única, mas de um conjunto de sinais e sintomas com alguns pontos em comum relacionados diretamente ao contexto socioeconômico, cultural e legal das diferentes sociedades ${ }^{2}$. Nessa perspectiva, há consenso de que o transtorno mental abrange distintos tipos de enfermidades e retardamento mentais, distúrbios de personalidade e dependência de substâncias ${ }^{3}$.

O relatório de estatísticas de saúde da Organização Mundial da Saúde (OMS) publicado em 2016 revelou que uma em cada dez pessoas é acometida por transtornos mentais, especialmente ansiedade e depressão. A depressão pode levar ao suicídio que, em 2012, representou 8,5\% das mortes em todo o mundo em adultos jovens de 15 a 29 anos. Com relação ao abuso de substâncias, que pode ter ligação com os transtornos mentais citados, em 2010, 16\% das pessoas com mais de 15 anos consumiram álcool excessivamente, o que pode onerar os sistemas públicos de saúde globais ${ }^{4}$.

As pessoas com transtornos mentais têm seu sofrimento acentuado pelo estigma, pela estereotipagem, pelo preconceito, pela rejeição, pela discriminação e pelos maus-tratos que persistem ao longo da história da saúde mental ${ }^{5,6}$, apesar dos

\footnotetext{
${ }^{1}$ ORGANIZAÇÃO DAS NAÇÕES UNIDAS - ONU. Declaração Universal dos Direitos Humanos: adotada e proclamada pela resolução 217 A (III) da Assembleia Geral das Nações Unidas em 10 de dezembro de 1948. Brasília-DF, 1998. Disponível em: http://unesdoc.unesco.org/images/0013/001394/139423por. pdf. Acesso em: 15 nov. 2017.

2ORGANIZAÇÃO MUNDIAL DA SAÚDE - OMS. Livro de recursos da OMS sobre saúde mental, direitos humanos e legislação. Genebra, 2005. Disponivel em: http://www.who.int/mental_health/policy/ Livroderecursosrevisao_FINAL.pdf. Acesso em: 15 nov. 2017.

${ }^{3} / d$. Ibid.

${ }^{4}$ WORLD HEALTH ORGANIZATION - WHO. World health statistics - monitoring health for the SDGs, sustainable development goals. Geneva, 2016. Disponivel em: http://www.who.int/gho/publications/world_health_ statistics/2016/en/. Acesso em: 16 nov. 2017.

${ }^{5}$ AMARANTE, P. Loucura, cultura e subjetividade: conceitos e estratégias, percurso e atores da Reforma Psiquiátrica brasileira. In: FLEURY, S. (Org.). Saúde e democracia: a luta do CEBES. São Paulo: Lemos Editorial, 1997. p. 163-185.

${ }^{6}$ CHAMMA, Rita de Cássia; FORCELLA, Hideko Takeuchi. 0 cidadão com transtorno psíquico: reflexões sobre os direitos humanos e os direitos do paciente. Revista da Escola de Enfermagem USP, São Paulo, v. 35, n. 2, p. 184-190, jun. 2001. http://dx.doi.org/10.1590/S0080-62342001000200014. Disponivel em: http:// www.scielo.br/pdf/reeusp/v35n2/v35n2a13.pdf. Acesso em: 16 nov. 2017.
} 
esforços da Lei n. 10.216/2001 (Lei da Reforma Psiquiátrica) para garantir tratamento humanizado a fim de recuperar a saúde dessas pessoas e protegê-las contra qualquer forma de abuso e exploração ${ }^{7}$.

Essas situações podem representar violações aos direitos humanos, incluindo os direitos civis, políticos, sociais, culturais e econômicos desse grupo vulnerável da população ${ }^{8}$. Importante ressaltar que os direitos civis dizem respeito às liberdades individuais: disposição do próprio corpo, locomoção, segurança, pensamento e fé, bem como os direitos à propriedade e à justiça. Os direitos políticos garantem a participação dos indivíduos no exercício do poder político, ora como membros de partidos, sindicatos e associações, ora como seus eleitores ${ }^{9,10}$. Já os direitos sociais, culturais e econômicos referem-se ao estabelecimento de padrões dignos de vida, que incluem todos os aspectos relacionados à saúde, ao gozo do progresso científico, à participação social e à proteção do patrimônio histórico-cultural, preservando valores, legados e tradições ${ }^{11,12,13}$.

O tema dos direitos humanos ganhou destaque na área da saúde mental com o combate à ditadura e com as lutas sociais para a redemocratização do Brasil, que garantiram esses direitos a todos os cidadãos. Nesse processo de transformação, a Reforma Psiquiátrica defendeu a mudança do modelo de atenção manicomial para um modelo de serviços comunitários, tais como Centros de Atenção Psicossocial (CAPS), residências terapêuticas, centros de convivência, enfermarias de saúde mental em hospitais gerais, oficinas de geração de renda, que estimulassem a reinserção social, o exercício da cidadania e a autonomia para a vida ${ }^{14,15}$. Contudo, hospitais especializados continuam oferecendo assistência psiquiátrica a pessoas com transtornos mentais, especialmente em situações de crise, de forma a ainda

${ }^{7}$ BRASIL. Lei n. 10.216, de 6 de abril de 2001. Dispõe sobre a proteção e os direitos das pessoas portadoras de transtornos mentais e redireciona o modelo assistencial em saúde mental. Diário Oficial da União, Brasília-DF, 9 abr. 2001. Disponível em: http://www.planalto.gov.br/ccivil_03/leis/leis_2001/l10216.htm. Acesso em: 18 nov. 2016.

${ }^{8}$ AMARANTE, P. op. cit.

${ }^{9}$ FERNANDES, Angela Viana Machado; PALUDETO, Melina Casari. Educação e direitos humanos: desafios para a escola contemporânea. Cadernos CEDES, Campinas, v. 30, n. 81, p. 233-249, maio/ago. 2010. http://dx.doi.org/10.1590/S0101-32622010000200008. Disponível em: http://www.scielo.br/pdf/ ccedes/v30n81/a08v3081.pdf. Acesso em: 15 jan. 2018.

${ }^{10}$ MANZINI-COVRE, Maria de Lourdes. O que é cidadania. 3. ed. São Paulo: Brasiliense, 2007.

${ }^{11}$ ABRAMOVICH, Víctor. E. Linhas de trabalho em direitos econômicos, sociais e culturais: instrumentos e aliados. Sur. Revista Internacional de Direitos Humanos, São Paulo, v. 2, n. 2, p. 189-223, 2005. http:// dx.doi.org/10.1590/S1806-64452005000100009. Disponível em: http://www.scielo.br/pdf/sur/v2n2/ a09v2n2.pdf. Acesso em: 18 nov. 2017.

${ }^{12}$ CLAUDE, Pierre. Direito à educação e educação para os direitos humanos. Sur: Revista Internacional de Direitos Humanos, São Paulo, v. 2, n. 2, p. 37-64, 2005. http://dx.doi.org/10.1590/S1806-64452005000100003. Disponível em: http://www.scielo.br/pdf/sur/v2n2/a03v2n2.pdf. Acesso em: 19 nov. 2017.

${ }^{13}$ FERNANDES, Angela Viana Machado; PALUDETO, Melina Casari. op. cit.

${ }^{14}$ MINISTÉRIO DA SAÚDE - MS. Secretaria de Atenção à Saúde. Departamento de Atenção Básica. Saúde mental. Brasília-DF, 2013. (Cadernos de Atenção Básica, 34). Disponível em: http://189.28.128.100/dab/ docs/portaldab/publicacoes/caderno_34.pdf. Acesso em: 20 nov. 2017.

${ }^{15}$ CHAMMA, Rita de Cássia; FORCELLA, Hideko Takeuchi. op. cit. 
constituírem estabelecimentos essenciais inseridos no modelo de assistência à saúde mental vigente no Brasil.

Independentemente do tipo de serviço de saúde mental, os profissionais que trabalham nas instituições que o prestam, as autoridades públicas e as famílias das pessoas com transtornos mentais têm o dever de zelar pelos direitos humanos desses indivíduos, nos termos da legislação civil brasileira ${ }^{16}$. Nesse cenário, o presente estudo apresentou como objetivo identificar a compreensão dos profissionais de saúde sobre os direitos humanos de pessoas com transtornos mentais em um hospital especializado do interior paulista.

\section{Método}

Trata-se de pesquisa descritiva com abordagem qualitativa, guiada pelo referencial da proteção internacional dos direitos humanos. O estudo foi realizado em um hospital estadual no interior de São Paulo que promove a internação de pessoas com transtornos mentais no modelo comunitário de cuidado e gestão em saúde mental.

Os dados foram coletados por meio de entrevistas semiestruturadas com profissionais de diversas categorias que participam do processo de internação e realizam cuidados diretos ao paciente ${ }^{17}$. As entrevistas foram realizadas em 2014 com 26 trabalhadores, que receberam orientação detalhada sobre o objetivo do estudo e assinaram o Termo de Consentimento Livre e Esclarecido. As entrevistas foram realizadas em local reservado e de acordo com a disponibilidade dos entrevistados, e o estudo foi aprovado pelo Comitê de Ética da Escola de Enfermagem de Ribeirão Preto, sob o n. 101/2014, segundo as regras da Resolução n. 466/2012 ${ }^{18}$.

As entrevistas foram realizadas com base em um roteiro de questões relacionadas à compreensão dos participantes sobre os direitos humanos das pessoas com transtornos mentais: Você conhece os direitos humanos de seus pacientes? Que direitos você acha que eles têm? Na sua opinião, é importante conhecer estes direitos? Você acha que neste momento esses direitos são respeitados? Se não, o que você acha que pode ser feito para melhorar esta situação? Já presenciou alguma situação de desrespeito aos direitos dos pacientes? Você acredita que pessoas com transtornos mentais possam conviver normalmente em sociedade?

\footnotetext{
${ }^{16}$ JUNGES, José Roque. A concepção Kantiana da dignidade humana. Estudos Jurídicos, São Leopoldo, v. 40, n. 2, p. 84-87, jul./dez. 2007.

${ }^{17}$ BRITO, Emanuele Seicenti de; VENTURA, Carla Aparecida Arena. 0 acesso às informações sobre diagnóstico e internação à pessoa com transtorno mental. SMAD. Revista Eletrônica Saúde Mental Álcool Drogas, Ribeirão Preto, v. 11, n. 1, p. 11-18, mar. 2015. http://dx.doi.org/10.11606/issn.1806-6976.v11i1p10-18. Disponível em: http://pepsic.bvsalud.org/pdf/smad/v11n1/pt_03.pdf. Acesso em: 20 nov. 2017.

${ }^{18}$ MINISTÉRIO DA SAÚDE - MS. Conselho Nacional de Saúde. Resolução n. 466, de 12 de dezembro de 2012. Aprova as diretrizes e normas regulamentadoras de pesquisas envolvendo seres humanos. 2012. Disponível em: http://bvsms.saude.gov.br/bvs/saudelegis/cns/2013/res0466_12_12_2012.html. Acesso em: 21 nov. 2017.
} 
As entrevistas foram gravadas e, posteriormente, transcritas e interpretadas por meio da análise de conteúdo na vertente temática, que consiste em descobrir núcleos de sentido semelhantes, cuja frequência e presença revelem temas e categorias significativos para o objeto em estudo ${ }^{19}$. As falas dos profissionais foram identificadas pela letra $\mathrm{P}$, seguida por uma sequência crescente de números cardinais que indica a ordem de realização das entrevistas e representam, portanto, os temas emergentes do conjunto de profissionais de saúde que aceitaram participar do estudo.

A análise temática desdobrou-se em três etapas: (i) pré-análise, na qual se organizaram e determinaram os núcleos de sentido e os recortes das falas; (ii) exploração do material, na qual os recortes e núcleos de sentido foram reduzidos em unidades temáticas, realizando-se a leitura exaustiva e repetida das entrevistas em função dos objetivos do estudo; e (iii) tratamento e interpretação dos resultados com subsídio de literatura pertinente, culminando em inferências e (iv) considerações finais ${ }^{20}$.

\section{Resultados e discussão}

Participaram do estudo 26 profissionais de saúde, sendo: dois médicos, quatro enfermeiros, oito técnicos de enfermagem, sete auxiliares de enfermagem, um psicólogo, um terapeuta ocupacional e três assistentes sociais. Dentre os profissionais, 20 eram do sexo feminino, 15 eram casados, 14 tinham tempo de trabalho na profissão de até 10 anos, e oito tinham tempo de trabalho no hospital de até 10 anos.

Emergiram da análise dos dados três unidades temáticas: Profissionais de saúde mental e os direitos humanos das pessoas com transtornos mentais; Conhecimento sobre direitos humanos e exercício da cidadania das pessoas com transtornos mentais; e Atitudes com relação aos direitos humanos das pessoas com transtornos mentais.

\section{Unidade temática 1: Profissionais de saúde mental e os direitos humanos das pessoas com transtornos mentais}

Os participantes do estudo conceituaram os direitos humanos das pessoas com transtornos mentais, exemplificando-os nas categorias dos direitos civis, políticos e sociais, semelhantemente aos achados de Ventura, Moraes e Jorge ${ }^{21,22}$. Houve

\footnotetext{
${ }^{19}$ MINAYO, Maria Cecília de Souza. O desafio do conhecimento: pesquisa qualitativa em saúde. 14. ed. São Paulo: Hucitec, 2014.

${ }^{20}$ Id. Ibid.

${ }^{21}$ VENTURA, Carla Aparecida Arena; MORAES, Viviana Carolina Oyan de; JORGE, Márjore Serena. Os profissionais de saúde e o exercício dos direitos humanos por portadores de transtornos mentais. Revista Eletrônica de Enfermagem, Goiânia, v. 15, n. 4, p. 854-861, out./dez. 2013. http://dx.doi.org/10.5216/ree.v15i4.19746. Disponível em: https://www.fen.ufg.br/fen_revista/v15/n4/v15n4a01.htm. Acesso em: 21 nov. 2017.

${ }^{22}$ VENTURA, Carla Aparecida Arena; MORAES, Viviana Carolina Oyan de; JORGE, Márjore Serena. Direitos humanos de pessoas com transtornos mentais: perspectiva de profissionais e clientes. Revista Enfermagem UERJ, Rio de Janeiro, v. 25, p. e4344, 2016. http://dx.doi.org/10.12957/reuerj.2017.4344. Disponível em: http://www.epublicacoes.uerj.br/index.php/enfermagemuerj/article/view/4344/21713. Acesso em: 21 nov. 2017.
} 
ênfase no direito à saúde, no qual os entrevistados destacaram o atendimento adequado e o tratamento humanizado como forma de manter ou restabelecer a saúde:

[...] direito de atendimento clínico, psiquiátrico, todo tipo de direito à saúde. (P-3)

Bom, se a gente for pensar em termos de tratamento, eu acho que o direito que eles têm é de receber um tratamento adequado. (P-5)

[...] Tratamento humanizado que a gente fala hoje, direito de ficar com a família. (P-9)

Direito a um tratamento adequado, humanizado. (P-13)

Olha, eu acredito que eles [os portadores de transtornos mentais] têm direito de serem respeitados, cuidados e de receber tudo o que o SUS pode oferecer para o restabelecimento [da saúde] e para a qualidade de vida deles. (P-23)

As expressões "atendimento clínico", "tratamento humanizado", "tratamento adequado" e "receber tudo o que o SUS pode oferecer" remetem à afirmação de que as pessoas em sofrimento mental têm direito à assistência em todos os tipos de serviços de saúde, como qualquer outra pessoa. Entende-se, também, que "atendimento adequado e humanizado" representa um conjunto diversificado de ações de saúde que responde às demandas e necessidades, de distintas naturezas, construídas pela interação de múltiplos fatores em um determinado contexto de vida $^{23}$. Portanto, essas indicações parecem ultrapassar o padrão de ações e serviços de saúde pré-estabelecido para o atendimento e acompanhamento das pessoas com transtornos mentais, singularizando a produção do cuidado.

Esses aspectos estão alinhados aos princípios da transversalidade e do protagonismo dos sujeitos referidos pela Política Nacional de Humanização, que buscam valorizar a autonomia e a vontade das pessoas, trazendo-as para o centro do processo do cuidado e, assim, transformando as relações hierarquizadas que isolam as pessoas do planejamento e da execução dessas práticas ${ }^{24}$.

Apesar de essas considerações envolverem uma leitura mais ampliada e contextualizada dos transtornos mentais, ainda é comum encontrar situações de atendimento nas quais a condição mental suprime outras necessidades biológicas

\footnotetext{
${ }^{23}$ CAMPOS, Gastão Wagner de Sousa. Clínica e saúde coletiva compartilhadas: teoria Paidéia e reformulação ampliada do trabalho em saúde. In: CAMPOS, G. W. S. (Orgs.). Tratado de Saúde coletiva. 2. ed. São Paulo: Hucitec, 2014. cap. 2, p. 39-78.

${ }^{24}$ MINISTÉRIO DA SAÚDE - MS. Política Nacional de Humanização. Brasília-DF, 2013. Disponível em: http:// bvsms.saude.gov.br/bvs/publicacoes/politica_nacional_humanizacao_pnh_folheto.pdf.
} 
e sociais que exigem a intervenção de especialidades diversas ${ }^{25}$, o que fragmenta a assistência e reduz a pessoa aos cuidados pré-estabelecidos e específicos à área de saúde mental.

Esses aspectos estão em consonância com os princípios 1, 2 e 3 da Carta dos Direitos dos Usuários da Saúde, que asseguram o acesso ordenado e organizado ao sistema de saúde, bem como o tratamento adequado, efetivo e humanizado conforme as necessidades das pessoas com transtorno menta ${ }^{26}$.

Entende-se também que os participantes associaram, de maneira indireta, o direito à saúde das pessoas com transtornos mentais com os incisos I e II do artigo 2 da Lei n. 10.216/2001, que reforçam os princípios da Carta, acrescentando que todo esse processo deve beneficiar a saúde, alcançar a recuperação e (re)inserir essas pessoas em sua família, seu trabalho e sua comunidade.

A Lei n. 10.216/2001 é fruto de uma lenta formalização legislativa dos direitos humanos desse segmento populacional, especialmente entre 1890 e 1934, período no qual os legisladores brasileiros se preocuparam em excluir essas pessoas da sociedade, eximindo-as de qualquer tipo de empoderamento sociojurídico ${ }^{27,28}$.

Na contramão dessa determinação, a partir da década de 1990 as legislações, impulsionadas pelas reformas Sanitária e Psiquiátrica, reconheceram a pessoa portadora de transtorno mental como cidadã e buscaram compreender as relações estabelecidas entre ela, a doença, a sociedade e o Estado. Dessa forma, o objeto de intervenção na saúde mental tornou-se mais amplo e complexo, exigindo a reconstrução de práticas e saberes tradicionais para se compreender o processo saúde-doença e garantir a igualdade de direitos ${ }^{29,30}$.

Na perspectiva da igualdade perante a lei, os participantes afirmaram que os direitos humanos desse grupo populacional são os mesmos de qualquer outra pessoa, em consonância com os direitos preconizados pela Declaração Universal dos Direitos Humanos aprovada pela Assembleia Geral da ONU em 1948:

\footnotetext{
${ }^{25}$ CORREIA, Ludmila Cerqueira. Guia de direitos humanos: loucura cidadã. Salvador: AMEA, 2011.

${ }^{26}$ MINISTÉRIO DA SAÚDE - MS. Carta dos direitos dos usuários da saúde. 2. ed. Brasília-DF, 2007. Disponível em: http://bvsms.saude.gov.br/bvs/publicacoes/carta_direito_usuarios_2ed2007.pdf. Acesso em: 25 nov. 2017.

${ }^{27}$ MARCHEWKA, Tânia Maria Nava. Humanização na assistência à saúde mental no hospital geral: uma das alternativas terapêuticas da reforma psiquiátrica garantida pelos direitos humanos. Revista de Direito Sanitário, São Paulo, v. 8, n. 1, p. 43-60, mar./jun. 2007. http://dx.doi.org/10.11606/issn.2316-9044. v8i1p43-60. Disponível em: http://www.revistas.usp.br/rdisan/article/view/80040/83939. Acesso em: 23 nov. 2017.

${ }^{28}$ BRITO, Emanuele Seicenti de; VENTURA, Carla Aparecida Arena. Evolução dos direitos das pessoas portadoras de transtornos mentais: uma análise da legislação brasileira. Revista de Direito Sanitário, São Paulo, v. 13, n. 2, p. 41-63, jul./out. 2012. http://dx.doi.org/10.11606/issn.2316-9044.v13i2p41-63. Disponivel em: http://www.revistas.usp.br/rdisan/article/view/56228/59440. Acesso em: 22 nov. 2017.

${ }^{29}$ MARCHEWKA, T. M. N. op. cit.

${ }^{30}$ BRITO, Emanuele Seicenti de; VENTURA, Carla Aparecida Arena. Evolução dos direitos das pessoas portadoras de transtornos mentais: uma análise da legislação brasileira, cit.
} 
Eu acho que é igual, tanto [os direitos] dos pacientes quanto [os] de qualquer pessoa. (P-4)

Ele [o portador de transtorno mental] tem direitos como qualquer cidadão. (P-6)

Olha, todos que são direitos do ser humano, não precisa nem ser dos pacientes. (P-15)

Eles têm os mesmos direitos que qualquer pessoa, né? (P-22)

Todos nós temos os mesmos direitos humanos. (P-26)

As pessoas têm direitos iguais, mas realidades, oportunidades e condições de vida de ordens distintas. Tomando o sofrimento mental como uma dessas condições, as pessoas com esses transtornos, assim como outros grupos específicos da população, devem ter essas diferenças respeitadas e seus direitos, protegidos. $\mathrm{O}$ direito à igualdade, ou simplesmente a igualdade, deve abranger o direito e o respeito à singularidade, à subjetividade e à diferença para promover a dignidade dessas pessoas ${ }^{31,32}$.

Portanto, embora a igualdade e a dignidade sejam elementos essenciais para a concretização dos direitos humanos e para o desenvolvimento social, ainda representam desafios no Brasil, assim como em outros países de sistema democrático recente . $^{33}$.

Os participantes ainda referiram que a informação sobre a própria saúde também corresponde a um direito humano das pessoas em sofrimento mental:

Conhecer seu médico, saber quem cuida dele, do seu diagnóstico, a medicação que toma, tem que ter um ambiente terapêutico adequado. (P-4)

Ele tem direito de esclarecer as dúvidas quanto à doença, quanto ao tratamento, entendeu? [Acessar] o seu prontuário quando ele quiser é um direito dele. (P-17)

\footnotetext{
${ }^{31}$ CORREIA, Ludmila Cerqueira. op. cit.

${ }^{32}$ CORREIA JUNIOR, Rubens; VENTURA, Carla Arena. O tratamento dos portadores de transtorno mental no Brasil - da legalização da exclusão à dignidade humana. Revista de Direito Sanitário, São Paulo, v. 15 n. 1, p. 40-60, mar./jun. 2014. http://dx.doi.org/10.11606/issn.2316-9044.v15i1p40-60. Disponível em: http://www.revistas.usp.br/rdisan/article/view/82805/85760. Acesso em: 24 jan. 2018.

${ }^{33}$ ANDRADE, Mariana Dionísio. Direitos humanos das pessoas com deficiência mental: tratamento institucional no contexto brasileiro. Quaestio luris, Rio de Janeiro, v. 10, n. 2, p. 1226-1243, 2017. http:// dx.doi.org/10.12957/rqi.2017.25082. Disponível em: http://www.e-publicacoes.uerj.br/index.php/ quaestioiuris/article/view/25082/20504. Acesso em: 23 nov. 2017.
} 
Ele tem o direito de saber sobre a doença dele, saber sobre o uso das medicações, conversar com os médicos, abordar a equipe sempre que for necessário. A família também, de sempre querer marcar entrevista, de querer saber do paciente, [o paciente] tem o direito de falar com a família. (P-19)

De ter, assim, todas as informações sobre seu quadro clínico e psiquiátrico, se não ele, ser representado por alguém da família. (P-21)

O direito de saber e falar sobre sua condição, de acessar informações sobre seu estado de saúde, de ter opinião e ser reconhecido naquilo que expressa faz parte do direito à comunicação, à liberdade de expressão e a ter voz ${ }^{34}$. Entende-se que os participantes, ao citarem "conhecer seu médico", "acessar seu prontuário", "conversar com os médicos e abordar a equipe", fazem referência à mediação da informação pelos profissionais de saúde, que são os intermediários na comunicação e elementos-chave para a apropriação das informações pelos usuários do serviço ${ }^{35,36}$.

Aqui, as informações de saúde são tomadas como conjunto de dados relacionados a diagnóstico, prognóstico, resultados de exames, prescrições e interações medicamentosas que propiciem o conhecimento sobre os direitos das pessoas, empoderando-as sobre os aspectos de sua saúde e trazendo possibilidades para exercer sua cidadania ${ }^{37}$.

Entretanto, estudo recente revela que o acesso a esse conjunto de dados pelas pessoas com transtornos mentais em hospital psiquiátrico é limitado. Embora sejam disponibilizadas, as informações são insuficientes devido à falta de tempo dos profissionais de saúde para oferecer atenção individualizada e à dificuldade de compreensão das pessoas nessas condições ${ }^{38}$.

\section{Unidade temática 2: Conhecimento dos direitos humanos e exercício da cidadania das pessoas com transtornos mentais}

Os profissionais entrevistados na pesquisa consideram relevante que as pessoas portadoras de transtornos mentais conheçam os direitos humanos individuais e sociais para cobrarem dos responsáveis a sua garantia e respeito:

\footnotetext{
${ }^{34}$ CORREIA, Ludmila Cerqueira. op. cit.

${ }^{35}$ LEITE, Renata Antunes Figueiredo et al. Acesso à informação em saúde e cuidado integral: percepção dos usuários de um serviço público. Interface - Saúde, Educação, Comunicação, v. 18, n. 51, p. 661-671, 2014. http://dx.doi.org/10.1590/1807-57622013.0653. Disponivel em: http://www.scielo.br/pdf/icse/ v18n51/1807-5762-icse-1807-576220140653.pdf. Acesso em: 23 nov. 2017.

${ }^{36}$ VENTURA, Carla Aparecida Arena; MORAES, Viviana Carolina Oyan de; JORGE, Márjore Serena. Direitos humanos de pessoas com transtornos mentais: perspectiva de profissionais e clientes, cit.

${ }^{37}$ LEITE, Renata Antunes Figueiredo et al. op. cit.

${ }^{38}$ BRITO, Emanuele Seicenti de; VENTURA, Carla Aparecida Arena. 0 acesso às informações sobre diagnóstico e internação à pessoa com transtorno mental, cit.
} 
Eu acho que, quanto mais conhecimento você tem, mais você exige. Se você não tem conhecimento, então você não sabe dos seus direitos. (P-3)

Ah, eu acho que quem conhece os seus direitos tem como se defender melhor de tudo. Eu acho que, se eles conhecem os direitos deles, eles vão poder aproveitar melhor o tratamento, vão poder exigir mais alguma coisa. (P-4)

Porque eles têm que ser esclarecidos dos direitos que eles têm, não podem ser tratados na instituição de qualquer jeito. (P-15)

Quando a gente sabe dos direitos, fica mais fácil exigir, né? (P-26)

Nas falas, evidencia-se que o "conhecimento", o "esclarecimento" e o "saber" ajudam as pessoas a se responsabilizarem por sua vida e reivindicarem seus diversos direitos. Porém, ainda hoje, é muito comum que boa parte da população não tenha conhecimento de seus direitos, situação esta que não se restringe às pessoas com transtornos mentais ${ }^{39}$.

Apesar de a Constituição Federal de $1988(\mathrm{CF} / 88)^{40}$ prever os direitos de qualquer pessoa, não havia, antes dela, o reconhecimento legislativo dos direitos das pessoas com transtornos mentais. Isso só foi alterado com a Reforma Psiquiátrica, que lhes assegurou a condição de sujeitos de direitos ${ }^{41}$. Entende-se que a normatização dos direitos humanos, por si só, não tem a capacidade de alterar imediatamente a consciência sobre o assunto, mas constitui instrumento a ser utilizado para reverter essa realidade ${ }^{42}$.

Estudos recentes revelam que pessoas com transtornos mentais frequentadoras de Centros de Atenção Psicossocial (CAPS) não sabem os diferentes direitos individuais e sociais que possuem ou não os conhecem claramente, portanto não se sentem capazes de exigi-los. Nesse cenário, as autoras afirmam que, apesar de o aparato normativo garantir esses direitos e de os profissionais de saúde reconhecerem a importância da conscientização sobre eles e de seu exercício, a falta de conhecimento das pessoas com transtornos

\footnotetext{
${ }^{39}$ CORREIA, Ludmila Cerqueira. op. cit.

${ }^{40}$ BRASIL. Constituição da República Federativa do Brasil de 1988. Disponível em: http://www.planalto.gov. br/ccivil_03/constituicao/constituicaocompilado.htm. Acesso em: 09 set. 2019.

${ }^{41}$ ld. Ibid.

${ }^{42}$ VENTURA, Carla Aparecida Arena; MELLO, Débora Falleiros de; ANDRADE, Raquel Dully; MENDES, Isabel Amélia Costa. Aliança da enfermagem com o usuário na defesa do SUS. Revista Brasileira de Enfermagem, Brasília, v. 65, n. 6, p. 893-398, nov./dez. 2012. http://dx.doi.org/10.1590/S003471672012000600002. Disponível em: http://www.scielo.br/pdf/reben/v65n6/a02v65n6.pdf. Acesso em: 23 nov. 2017.
} 
mentais é real ${ }^{43,44}$. Portanto, os profissionais de saúde podem atuar como educadores, no sentido de compartilhar conhecimento, desenvolver a consciência e conduzir ao respeito e à consolidação de direitos ${ }^{45}$, tal como os fragmentos a seguir exprimem:

Quando a gente tem conhecimento dos direitos das pessoas e dos pacientes, a gente consegue lidar melhor com o problema de cada um, individualmente. [...]. Então são pacientes que, quanto mais a gente souber dos direitos, quanto mais a gente puder ajudá-los a ter os direitos garantidos, melhor para todo mundo. (P-22)

É sim. É importante [conhecer os direitos dos pacientes] para a gente poder garantir isso, porque muitas vezes eles não têm condições de exigir e é nosso papel auxiliar nisso também [...]. (P-25)

De acordo com Tavares ${ }^{46}$, a educação é o caminho para qualquer mudança social. A educação em direitos humanos é um processo contínuo, sempre em renovação, e implementá-la requer a compreensão do significado e da práxis dos direitos. Ela permite sensibilizar e conscientizar as pessoas para a importância do respeito ao ser humano, apresentando-se, na atualidade, como uma ferramenta fundamental na construção da cidadania e na afirmação de tais direitos ${ }^{47}$.

As pessoas que gozam da educação em direitos humanos são capazes de atuar frente às injustiças e desigualdades, reconhecendo a autonomia e a igualdade, dentro dos preceitos de diversidade e tolerância, e valorizando a convivência harmoniosa, o respeito mútuo e a solidariedade ${ }^{48}$.

No Brasil, a educação em direitos humanos é um campo recente, que ainda não atinge a totalidade da população tampouco está inserida no processo de formação dos profissionais de saúde, apesar de documentos nacionais ${ }^{49}$ e internacionais tratarem sobre a necessidade de sua implementação ${ }^{50}$. Relatório do Instituto Interamericano de Direitos Humanos (IIDH) aponta que, desde a Declaração Universal de Direitos Humanos de 1948, vem se reafirmando a educação como direito universal e

${ }^{43}$ BRITO, Emanuele Seicenti de; VENTURA, Carla Aparecida Arena. Evolução dos direitos das pessoas portadoras de transtornos mentais: uma análise da legislação brasileira, cit.

${ }^{44}$ VENTURA, Carla Aparecida Arena; MORAES, Viviana Carolina Oyan de; JORGE, Márjore Serena. Direitos humanos de pessoas com transtornos mentais: perspectiva de profissionais e clientes, cit.

${ }^{45}$ VENTURA, Carla Aparecida Arena; MELLO, Débora Falleiros de; ANDRADE, Raquel Dully; MENDES, Isabel Amélia Costa. op. cit.

${ }^{46}$ TAVARES, C. Educar em direitos humanos, o desafio da formação dos educadores numa perspectiva interdisciplinar. In: SILVEIRA, R. M. G. et al. (Orgs.). Educação em direitos humanos: fundamentos teóricometodológicos. João Pessoa: Editora Universitária, 2007. cap. 7, p. 487-503.

${ }^{47}$ Id. Ibid.

${ }^{48}$ Id. Ibid. 
a educação em direitos humanos, como integrante desse direito ${ }^{51}$, conforme o item 2 do artigo 13 do Protocolo de San Salvador, de 1988:

[...] A educação deverá orientar-se para o pleno desenvolvimento da personalidade humana e do sentido de sua dignidade e deverá fortalecer o respeito pelos direitos humanos, pelo pluralismo ideológico, pelas liberdades fundamentais, pela justiça e pela paz. [...] A educação deve capacitar todas as pessoas para participar efetivamente de uma sociedade democrática e pluralista, conseguir uma subsistência digna, favorecer a compreensão, a tolerância e a amizade entre todas as nações e todos os grupos raciais, étnicos ou religiosos e promover as atividades em prol da manutenção da paz ${ }^{52}$.

Por um lado, as falas aqui reproduzidas revelam o papel dos profissionais na educação e orientação das pessoas com transtornos mentais sobre seus direitos. Por outro, se forem considerados os termos "garantir" como sinônimo de assegurar e "respeitar" como sinônimo de obedecer ou cumprir, pode-se correlacionar conhecimento, conscientização e respeito aos direitos humanos:

Sim, [é importante conhecer os direitos dos pacientes] para as pessoas se conscientizarem e aplicar, né? De fato, fazer valer o direito das pessoas [...]. (P-5)

Sim, é importante [conhecer os direitos dos pacientes]. Através dele [do conhecimento], a gente consegue fazer um tratamento mais adequado e respeitando os direitos para que ele [o paciente] tenha um tratamento diferenciado [...]. (P-13)

Entende-se que garantir ou assegurar os direitos humanos por meio de normas, leis, portarias e tratados não necessariamente significa respeitar a legislação nem promover esses direitos e a cidadania das pessoas com transtornos mentais. Nesse sentido, violações aos direitos humanos, seja por discriminação, seja por diferenciação, seja por exclusão, podem estar presentes no dia a dia e comprometer a assistência em saúde mental ${ }^{53,54}$.

\footnotetext{
${ }^{51}$ INSTITUTO INTERAMERICANO DE DIREITOS HUMANOS - IIDH. Relatório interamericano de educação em direitos humanos: um estudo em 19 países, desenvolvimento nas políticas de convivência e segurança escolar com enfoque de direitos. San Jose, 2011. Disponível em: https://www.iidh.ed.cr/IIDH/media/1526/ x-informe-portugues-2011.pdf. Acesso em: 21 jan. 2018.

${ }^{52}$ COMISSÃO INTERAMERICANA DE DIREITOS HUMANOS - CIDH. Protocolo adicional à Convenção Americana sobre Direitos Humanos em matéria de direitos econômicos, sociais e Culturais, "Protocolo de San Salvador". 1988. Disponível em: http://www.cidh.org/basicos/portugues/e.protocolo_de_san_salvador. htm. Acesso em: 21 jan. 2018.

${ }^{53}$ BRESSAN, Regina Bressan; MARCOLAN, João Fernando. O desvelar de violações dos direitos humanos em serviços residenciais terapêuticos. Psicologia em Estudo, Maringá, v. 21, n. 1, p. 149-160, jan./mar. 2016. Disponivel em: http://www.redalyc.org/pdf/2871/287146384016.pdf. Acesso em: 22 jan. 2018.

${ }^{54}$ CORREIA, Ludmila Cerqueira. op. cit.
} 


\section{Unidade temática 3: Atitudes dos profissionais com relação aos direitos humanos das pessoas com transtornos mentais}

Nas entrevistas, os profissionais mencionaram atitudes mais reativas com relação ao cuidado das pessoas com transtornos mentais, o que sugere a falta de respeito aos diferentes direitos dos pacientes:

Não dá para você ter certeza que todos os profissionais da área conseguem dar ao paciente tudo aquilo que ele merece porque nem todos os profissionais [...] entendem o que é isso. (P-1)

$\mathrm{Eu}$, como profissional, procuro respeitar o direito dos pacientes até o ponto que eu sei onde é o direito deles [...]. (P-23)

Olha, eu acredito que tem algumas pessoas, no caso da saúde mental, que não têm preparo para lidar com pacientes com transtorno mental, né? (P-7)

A maioria dos participantes citou, brevemente, já ter presenciado situações de desrespeito aos direitos dessas pessoas no serviço de saúde, porém suas falas não explicitaram ocorrências concretas. Estudos recentes mostram que essas atitudes geralmente são praticadas por cuidadores e trabalhadores de saúde em instituições de saúde mental ${ }^{55}$, por pessoas comuns em meio à sociedade civil ${ }^{56,57}$ e por curadores e promotores de justiçą ${ }^{58}$.

Além da literatura científica, a Associação Brasileira de Pós-graduação em Saúde Coletiva (Abrasco), criada com o objetivo de apoiar, articular e ampliar o diálogo entre a comunidade técnico-científica, os serviços de saúde, as organizações governamentais/não governamentais e a sociedade civil, também divulgou e discutiu com especialistas casos recentes de tortura, maus-tratos, mortes em hospitais psiquiátricos e abrigos em Niterói (RJ), Jarinu (SP), Campo Limpo Paulista (SP) e em Cariacica $(\mathrm{ES})^{59}$.

Além da violação derivada do cuidado direto às pessoas, a própria internação, quando involuntária ou compulsória, pode representar desrespeito aos direitos à liberdade e à autonomia das pessoas com transtornos mentais, especialmente

\footnotetext{
${ }^{55}$ BRESSAN, Regina Bressan; MARCOLAN, João Fernando. op. cit.

${ }^{56}$ BRITO, Emanuele Seicenti de; VENTURA, Carla Aparecida Arena. Evolução dos direitos das pessoas portadoras de transtornos mentais: uma análise da legislação brasileira, cit.

${ }^{57}$ VENTURA, Carla Aparecida Arena; MORAES, Viviana Carolina Oyan de; JORGE, Márjore Serena. Direitos humanos de pessoas com transtornos mentais: perspectiva de profissionais e clientes, cit.

${ }^{58}$ CARVALHO, Sandra Maciel de; PERUCCHI, Juliana. "Não converso com demente": intersecções entre direito e saúde mental. Psicologia: Ciência e Profissão

${ }^{59}$ QUARESMA, Flaviano. Torturas, maus-tratos, mortes em hospitais psiquiátricos e abrigos. Até quando? ABRASCO Notícias, Rio de Janeiro, 25 jul. 2017. Disponível em: https://www.abrasco.org.br/site/ noticias/saude-da-populacao/torturas-maus-tratos-mortes-em-hospitais-psiquiatricos-e-abrigos-atequando/29744/. Acesso em: 20 jan. 2018.
} 
quando seu discernimento, sua consciência e seu juízo estão alterados. Estudo recente ${ }^{60}$ aponta que as internações involuntárias ou compulsórias são uma possibilidade para garantir o atendimento clínico aos portadores de transtornos mentais e amenizar o sofrimento individual e familiar quando as outras formas de enfrentamento do transtorno mental se esgotaram. Entretanto, as autoras ressaltam que, para implementar qualquer modalidade de internação psiquiátrica, é essencial avaliar o contexto de vida e a singularidade das pessoas portadoras de transtorno mental.

Bressan e Marcolan ${ }^{61}$ afirmam que a ignorância, a falsa crença sobre os portadores de sofrimento psíquico, a falta de capacitação, de conhecimento, de educação permanente e de supervisão dos profissionais e a precarização do trabalho concorrem para a violação dos direitos humanos.

Os autores descreveram, ainda, relatos de violência física, verbal, psicológica e sexual, bem como negligência de cuidados por parte de profissionais de serviços de saúde mental em Minas Gerais, Brasil. Essas práticas mostraram-se influenciadas pela concepção social da loucura que, ainda hoje, associa o paciente psiquiátrico à falta de compreensão, de inteligência, de autonomia e de razão e à exclusão, à discriminação e ao isolamento social ${ }^{62}$.

Apesar de não serem raras, a maior parte das violações aos direitos humanos é denunciada e tem sido investigada por órgãos competentes, tais como Conselho Regional de Enfermagem de São Paulo, Ministério Público e Polícia Civil ${ }^{63,64}$, além de gestão municipal de saúde responsável pelos serviços ${ }^{65}$.

E, nesse contexto, Bressan e Marcolan ${ }^{66}$ e Chamma e Forcella ${ }^{67}$ sugerem que as instituições de assistência psiquiátrica implantem critérios para admissão de pessoal, ofereçam treinamento, atualização e educação em serviço, bem como condições adequadas de trabalho que ajudem a garantir a qualidade da assistência em saúde mental, e extingam as práticas manicomiais que ainda parecem ser hegemônicas em nossa sociedade.

\footnotetext{
${ }^{60}$ XAVIER, Mariane da Silva et al. Compreensão de enfermeiras atuantes em saúde mental sobre a internação compulsória e involuntária. Esc. Anna Nery, Rio de Janeiro, v. 21, n. 3, e20160262, 2017. http://dx.doi.org/10.1590/2177-9465-ean-2016-0262. Disponível em: http://www.scielo. br/scielo.php?script=sci_arttext\&pid=S1414-81452017000300202\&lng=pt\&nrm=iso. Acesso em: 18 set. 2018.

${ }^{61}$ BRESSAN, Regina Bressan; MARCOLAN, João Fernando. op. cit.

${ }^{62}$ Id. Ibid.

${ }^{63}$ CHAMMA, Rita de Cássia; FORCELLA, Hideko Takeuchi. op. cit.

${ }^{64}$ QUARESMA, Flaviano. op. cit.

${ }^{65}$ BRESSAN, Regina Bressan; MARCOLAN, João Fernando. op. cit.

${ }^{66}$ Id. Ibid.

${ }^{67}$ CHAMMA, Rita de Cássia; FORCELLA, Hideko Takeuchi. op. cit.
} 


\section{Considerações finais}

A partir dos discursos destacados nas unidades temáticas, podemos concluir que os profissionais de saúde do hospital especializado estudado reconheceram as pessoas com transtornos mentais como portadoras de direitos inalienáveis, apontando como direitos humanos os direitos civis, políticos e sociais. Destacaram o direito à assistência em saúde humanizada e adequada, à informação sobre sua saúde, à igualdade e à dignidade.

Os profissionais apontaram ser relevante o conhecimento dos direitos humanos pelas pessoas com transtornos mentais para exigirem a garantia desses direitos e o respeito a eles. Alguns profissionais assumiram seu papel de educadores nesse cenário, e outros explicitaram uma conexão entre o conhecimento e a conscientização sobre esses direitos e o respeito a eles.

Os participantes apontaram que a falta de conhecimento e de compreensão sobre os direitos humanos pode interferir no cuidado direto aos usuários do serviço. Ainda, a maioria dos profissionais relatou ter presenciado situações de violação dos direitos dos pacientes no atendimento de saúde mental.

As unidades temáticas possibilitariam várias formas de discutir a compreensão dos profissionais de saúde sobre os direitos humanos das pessoas com transtornos mentais. Optou-se por dialogar, brevemente, com a Carta dos Direitos dos Usuários da Saúde e com a Lei n. 10.216/2001, considerada um marco nas transformações sociojurídicas graças à luta anitmanicomial.

Admite-se que a pessoa com transtorno mental, assim como qualquer um de nós, vive, se relaciona, produz, se reproduz, adoece e morre socialmente, embora em contextos de vida particulares e não generalizáveis que exigem dos profissionais de saúde a compreensão dos múltiplos fatores que determinam uma doença e formam o indivíduo. Portanto, entendemos que o modelo de cuidado primário, ambulatorial ou hospitalar, restrito ao tratamento de uma doença pode não ser mais suficiente para alcançar os preceitos da Carta dos Direitos e da Lei n. 10.216/2001. De nada valerá sancionar legislações antimanicomiais se a realidade atual em distintas instituições de saúde ainda revela a violação dos direitos humanos das pessoas com transtornos mentais.

A discussão das unidades temáticas revelou que assistir e respeitar a pessoa com transtornos mentais pode requerer conhecimentos específicos, bem como atualização e educação continuada e permanente. Acredita-se que conhecer os direitos humanos desse grupo populacional, de outras minorias e das pessoas de modo geral é uma das vertentes que estruturam o cuidado e a educação em saúde prestados pelos profissionais aos usuários.

Admite-se que a escolha da técnica de coleta de dados permite novos questionamentos para além do roteiro pré-elaborado, entretanto essa possibilidade não 
foi densamente explorada, o que pode ter limitado a discussão dos resultados. Ainda assim, a realidade apresentada de maneira concisa pelos trabalhadores de saúde neste estudo pode contribuir com discussões técnico-científicas, ser confrontada e agregar novas experiências profissionais à rica e densa literatura sobre os direitos humanos das pessoas com transtornos mentais.

\section{Referências}

ABRAMOVICH, Víctor. E. Linhas de trabalho em direitos econômicos, sociais e culturais: instrumentos e aliados. Sur. Revista Internacional de Direitos Humanos, São Paulo, v. 2, n. 2, p. 189-223, 2005. http://dx.doi.org/10.1590/S1806-64452005000100009. Disponível em: http:// www.scielo.br/pdf/sur/v2n2/a09v2n2.pdf. Acesso em: 18 nov. 2017.

AMARANTE, P. Loucura, cultura e subjetividade: conceitos e estratégias, percurso e atores da Reforma Psiquiátrica brasileira. In: FLEURY, S. (Org.). Saúde e democracia: a luta do CEBES. São Paulo: Lemos Editorial, 1997. p. 163-185.

ANDRADE, Mariana Dionísio. Direitos humanos das pessoas com deficiência mental: tratamento institucional no contexto brasileiro. Quaestio Iuris, Rio de Janeiro, v. 10, n. 2, p. 1226-1243, 2017. http://dx.doi.org/10.12957/rqi.2017.25082. Disponível em: http:// www.e-publicacoes.uerj.br/index.php/quaestioiuris/article/view/25082/20504. Acesso em: 23 nov. 2017.

BRASIL. Ministério da Saúde. Secretaria de Atenção à Saúde. Política Nacional de Humanização. Brasília-DF, 2013. Disponível em: http://bvsms.saude.gov.br/bvs/publicacoes/ politica_nacional_humanizacao_pnh_folheto.pdf. Acesso em: 19 set. 2018.

BRESSAN, Regina Bressan; MARCOLAN, João Fernando. O desvelar de violações dos direitos humanos em serviços residenciais terapêuticos. Psicologia em Estudo, Maringá, v. 21, n. 1, p. 149-160, jan./mar. 2016. Disponível em: http://www.redalyc.org/pdf/2871/287146384016. pdf. Acesso em: 22 jan. 2018.

BRITO, Emanuele Seicenti de; VENTURA, Carla Aparecida Arena. Evolução dos direitos das pessoas portadoras de transtornos mentais: uma análise da legislação brasileira. Revista de Direito Sanitário, São Paulo, v. 13, n. 2, p. 41-63, jul./out. 2012. http://dx.doi.org/10.11606/ issn.2316-9044.v13i2p41-63. Disponível em: http://www.revistas.usp.br/rdisan/article/ view/56228/59440. Acesso em: 22 nov. 2017.

BRITO, Emanuele Seicenti de; VENTURA, Carla Aparecida Arena. O acesso às informações sobre diagnóstico e internação à pessoa com transtorno mental. SMAD. Revista Eletrônica Saúde Mental Álcool Drogas, Ribeirão Preto, v. 11, n. 1, p. 11-18, mar. 2015. http://dx.doi. org/10.11606/issn.1806-6976.v1lilp10-18. Disponível em: http://pepsic.bvsalud.org/pdf/ smad/v11n1/pt_03.pdf. Acesso em: 20 nov. 2017.

CAMPOS, Gastão Wagner de Sousa. Clínica e saúde coletiva compartilhadas: teoria Paidéia e reformulação ampliada do trabalho em saúde. In: CAMPOS, G. W. S. (Orgs.). Tratado de Saúde coletiva. 2. ed. São Paulo: Hucitec, 2014. cap. 2, p. 39-78. 
CARVALHO, Sandra Maciel de; PERUCCHI, Juliana. "Não converso com demente": intersecções entre direito e saúde mental. Psicologia: Ciência e Profissão, Brasília-DF, v. 36, n. 3, p. 584-596, jul./set. 2016. http://dx.doi.org/10.1590/1982-3703001332014. Disponível em: http://www.scielo.br/pdf/pcp/v36n3/1982-3703-pcp-36-3-0584.pdf. Acesso em: 23 jan. 2018.

CHAMMA, Rita de Cássia; FORCELLA, Hideko Takeuchi. O cidadão com transtorno psíquico: reflexões sobre os direitos humanos e os direitos do paciente. Revista da Escola de Enfermagem USP, São Paulo, v. 35, n. 2, p. 184-190, jun. 2001. http://dx.doi.org/10.1590/S008062342001000200014. Disponível em: http://www.scielo.br/pdf/reeusp/v35n2/v35n2a13.pdf. Acesso em: 16 nov. 2017.

CLAUDE, Pierre. Direito à educação e educação para os direitos humanos. Sur: Revista Internacional de Direitos Humanos, São Paulo, v. 2, n. 2, p. 37-64, 2005. http://dx.doi. org/10.1590/S1806-64452005000100003. Disponível em: http://www.scielo.br/pdf/sur/v2n2/ a03v2n2.pdf. Acesso em: 19 nov. 2017.

COMISSÃO INTERAMERICANA DE DIREITOS HUMANOS - CIDH. Protocolo adicional à Convenção Americana sobre Direitos Humanos em matéria de direitos econômicos, sociais e Culturais, "Protocolo de San Salvador". 1988. Disponível em: http://www.cidh.org/basicos/ portugues/e.protocolo_de_san_salvador.htm. Acesso em: 21 jan. 2018.

CORREIA JUNIOR, Rubens; VENTURA, Carla Arena. O tratamento dos portadores de transtorno mental no Brasil - da legalização da exclusão à dignidade humana. Revista de Direito Sanitário, São Paulo, v. 15 n. 1, p. 40-60, mar./jun. 2014. http://dx.doi.org/10.11606/ issn.2316-9044.v15i1p40-60. Disponível em: http://www.revistas.usp.br/rdisan/article/ view/82805/85760. Acesso em: 24 jan. 2018.

CORREIA, Ludmila Cerqueira. Guia de direitos humanos: loucura cidadã. Salvador: AMEA, 2011.

FERNANDES, Angela Viana Machado; PALUDETO, Melina Casari. Educação e direitos humanos: desafios para a escola contemporânea. Cadernos CEDES, Campinas, v. 30, n. 81, p. 233-249, maio/ago. 2010. http://dx.doi.org/10.1590/S0101-32622010000200008. Disponível em: http://www.scielo.br/pdf/ccedes/v30n81/a08v3081.pdf. Acesso em: 15 jan. 2018.

INSTITUTO INTERAMERICANO DE DIREITOS HUMANOS - IIDH. Relatório interamericano de educação em direitos humanos: um estudo em 19 países, desenvolvimento nas políticas de convivência e segurança escolar com enfoque de direitos. San Jose, 2011. Disponível em: https://www.iidh.ed.cr/IIDH/media/1526/x-informe-portugues-2011.pdf. Acesso em: 21 jan. 2018.

JUNGES, José Roque. A concepção Kantiana da dignidade humana. Estudos Jurídicos, São Leopoldo, v. 40, n. 2, p. 84-87, jul./dez. 2007.

LEITE, Renata Antunes Figueiredo et al. Acesso à informação em saúde e cuidado integral: percepção dos usuários de um serviço público. Interface - Saúde, Educação, Comunicação, v. 18, n. 51, p. 661-671, 2014. http://dx.doi.org/10.1590/1807-57622013.0653. Disponível em: http://www.scielo.br/pdf/icse/v18n51/1807-5762-icse-1807-576220140653.pdf. Acesso em: 23 nov. 2017. 
MANZINI-COVRE, Maria de Lourdes. O que é cidadania. 3. ed. São Paulo: Brasiliense, 2007.

MARCHEWKA, Tânia Maria Nava. Humanização na assistência à saúde mental no hospital geral: uma das alternativas terapêuticas da reforma psiquiátrica garantida pelos direitos humanos. Revista de Direito Sanitário, São Paulo, v. 8, n. 1, p. 43-60, mar./jun. 2007. http:// dx.doi.org/10.11606/issn.2316-9044.v8i1p43-60. Disponível em: http://www.revistas.usp.br/ rdisan/article/view/80040/83939. Acesso em: 23 nov. 2017.

MINAYO, Maria Cecília de Souza. O desafio do conhecimento: pesquisa qualitativa em saúde. 14. ed. São Paulo: Hucitec, 2014.

MINISTÉRIO DA SAÚDE - MS. Carta dos direitos dos usuários da saúde. 2. ed. BrasíliaDF, 2007. Disponível em: http://bvsms.saude.gov.br/bvs/publicacoes/carta_direito_ usuarios_2ed2007.pdf. Acesso em: 25 nov. 2017.

MINISTÉRIO DA SAÚDE - MS. Política Nacional de Humanização. Brasília-DF, 2013. Disponível em: http://bvsms.saude.gov.br/bvs/publicacoes/politica_nacional_humanizacao_pnh_folheto.pdf.

MINISTÉRIO DA SAÚDE - MS. Secretaria de Atenção à Saúde. Departamento de Atenção Básica. Saúde mental. Brasília-DF, 2013. (Cadernos de Atenção Básica, 34). Disponível em: http://189.28.128.100/dab/docs/portaldab/publicacoes/caderno_34.pdf. Acesso em:20 nov. 2017.

ORGANIZAÇÃO DAS NAÇÕES UNIDAS - ONU. Declaração Universal dos Direitos Humanos: adotada e proclamada pela resolução 217 A (III) da Assembleia Geral das Nações Unidas em 10 de dezembro de 1948. Brasília-DF, 1998. Disponível em: http://unesdoc.unesco. org/images/0013/001394/139423por.pdf. Acesso em: 15 nov. 2017.

ORGANIZAÇÃO MUNDIAL DA SAÚDE - OMS. Livro de recursos da OMS sobre saúde mental, direitos humanos e legislação. Genebra, 2005. Disponível em: http://www.who.int/ mental_health/policy/Livroderecursosrevisao_FINAL.pdf. Acesso em: 15 nov. 2017.

ORGANIZAÇÃO MUNDIAL DA SAÚDE - OMS. Livro de recursos da OMS sobre saúde mental, direitos humanos e legislação. Genebra, 2005. Disponível em: http://www.who.int/ mental_health/policy/Livroderecursosrevisao_FINAL.pdf. Acesso em: 15 nov. 2017.

QUARESMA, Flaviano. Torturas, maus-tratos, mortes em hospitais psiquiátricos e abrigos. Até quando? ABRASCO Notícias, Rio de Janeiro, 25 jul. 2017. Disponível em: https://www. abrasco.org.br/site/noticias/saude-da-populacao/torturas-maus-tratos-mortes-em-hospitaispsiquiatricos-e-abrigos-ate-quando/29744/. Acesso em: 20 jan. 2018.

TAVARES, C. Educar em direitos humanos, o desafio da formação dos educadores numa perspectiva interdisciplinar. In: SILVEIRA, R. M. G. et al. (Orgs.). Educação em direitos humanos: fundamentos teórico-metodológicos. João Pessoa: Editora Universitária, 2007. cap. 7, p. 487-503.

VENTURA, Carla Aparecida Arena et al. Aliança da enfermagem com o usuário na defesa do SUS. Revista Brasileira de Enfermagem, Brasília, v. 65, n. 6, p. 893-398, nov./dez. 2012. http://dx.doi.org/10.1590/S0034-71672012000600002. Disponível em: http://www.scielo.br/ pdf/reben/v65n6/a02v65n6.pdf. Acesso em: 23 nov. 2017. 
VENTURA, Carla Aparecida Arena; MELLO, Débora Falleiros de; ANDRADE, Raquel Dully; MENDES, Isabel Amélia Costa

VENTURA, Carla Aparecida Arena; MORAES, Viviana Carolina Oyan de; JORGE, Márjore Serena. Os profissionais de saúde e o exercício dos direitos humanos por portadores de transtornos mentais. Revista Eletrônica de Enfermagem, Goiânia, v. 15, n. 4, p. 854-861, out./ dez. 2013. http://dx.doi.org/10.5216/ree.v15i4.19746. Disponível em: https://www.fen.ufg. br/fen_revista/v15/n4/v15n4a01.htm. Acesso em: 21 nov. 2017.

VENTURA, Carla Aparecida Arena; MORAES, Viviana Carolina Oyan de; JORGE, Márjore Serena. Direitos humanos de pessoas com transtornos mentais: perspectiva de profissionais e clientes. Revista Enfermagem UERJ, Rio de Janeiro, v. 25, p. e4344, 2016. http://dx.doi. org/10.12957/reuerj.2017.4344. Disponível em: http://www.e-publicacoes.uerj.br/index.php/ enfermagemuerj/article/view/4344/21713. Acesso em: 21 nov. 2017.

WORLD HEALTH ORGANIZATION - WHO. World health statistics - monitoring health for the SDGs, sustainable development goals. Geneva, 2016. Disponível em: http://www.who.int/ gho/publications/world_health_statistics/2016/en/. Acesso em: 16 nov. 2017.

XAVIER, Mariane da Silva et al. Compreensão de enfermeiras atuantes em saúde mental sobre a internação compulsória e involuntária. Esc. Anna Nery, Rio de Janeiro, v. 21, n. 3, e20160262, 2017. http://dx.doi.org/10.1590/2177-9465-ean-2016-0262. Disponível em: http://www.scielo.br/scielo.php?script=sci_arttext\&pid=S1414-81452017000300202\&lng $=$ pt\&nrm=iso. Acesso em: 18 set. 2018 .

Carla Aparecida Arena Ventura - Livre-Docência pela Escola de Enfermagem de Ribeirão Preto da Universidade de São Paulo (EERP-USP); doutorado em Administração pela Universidade de São Paulo (USP); mestrado em Direito pela Universidade Estadual Paulista Júlio de Mesquita Filho (Unesp). Professora titular do Departamento de Enfermagem Psiquiátrica e Ciências Humanas da EERP-USP. Advogada. Ribeirão Preto/SP, Brasil. E-mail: caaventu@eerp.usp.br

Anna Maria Meyer Maciel Rodríguez - Doutorado e mestrado em Ciências pela Escola de Enfermagem de Ribeirão Preto da Universidade de São Paulo (EERP-USP). Enfermeira. Ribeirão Preto/SP, Brasil. E-mail: nimeyer5@hotmail.com

Elidia Aparecida Costa Bittencourt - Enfermeira. Ribeirão Preto/SP, Brasil.

Emanuele Seicenti de Brito - Doutorado e mestrado em Ciências pela Escola de Enfermagem de Ribeirão Preto da Universidade de São Paulo (EERP-USP). Advogada. Ribeirão Preto/SP, Brasil. 